\title{
Dynamic Model for the Stress and Strain State Analysis of a Spur Gear Transmission
}

\author{
Vera Nikolić1,* - Ćemal Dolićanin ${ }^{1}$ - Dejan Dimitrijević ${ }^{2}$ \\ 1 The State University of Novi Pazar, Serbia \\ 2 Simens, Germany
}

A gear transmission dynamic model for the gear dynamic contact loading, dynamic contact stress state and dynamic contact strain state analysis is presented. A dynamic model of the transmission with four degrees of freedom is used. The transmission is analyzed using nonlinear finite elements contact formulation, using a novel software modules developed by the author used for the generalized analysis of the geared transmissions in the environment of the open source finite elements framework CODE-ASTER/ SALOME.

(C)2011 Journal of Mechanical Engineering. All rights reserved.

Keywords: stress and strain state analysis, tensor invariants, finite element method, geared transmissions

\section{INTRODUCTION}

Gear transmissions have a long history dating back since the time of the first engineering systems. Their practical usage in the present day modern engineering systems is enormous. In accordance with a contemporary development of mechanical engineering techniques ever growing requirements have been imposed concerning characteristics and working specifications. The machines which utilize high-power duty gear transmissions (excavating machines, crushing machines, rolling machines, ships, etc.) operate under non-stationary conditions, so that the loads of the elements of these gear transmissions are variable. For example, abrupt accelerations and abrupt decelerations of machine parts, that is, masses of the gear transmissions cause inertial forces which, in addition to the conditions of operation, influence the magnitude of actual leads of the elements of gear transmissions. All this, together with the changes of the torque of drive and operating machine, the forces induced by dynamic behaviours of the complete system, etc., lead to a simulation where the stresses in the gears are higher than critical stresses; after certain time this may result in breakage of the teeth.

Internal dynamic forces are also present. During the teeth meshing action, internal dynamic forces occur because of the elastic tooth deformation and manufacturing errors (for example: tooth profile form tolerance errors and circular gear pitch difference). During the meshing action, tooth deformation can cause impact between gear teeth. Intensity of the impact between the teeth is dependent of circular pitch difference size. The bigger circular pitch difference, the more intensive is the impact between the gear teeth during the meshing action. The gear vibrations can also influence the internal dynamic forces between the gear teeth. The teeth in meshing action can be modelled as an oscillatory system [1] to [3]. This model consists of concentrated masses (each of which represent one gear) connected with elastic and dump element. Applying the basic principles of analytical mechanics and taking the initial and boundary conditions into consideration, it is possible to obtain the system of equations representing physical meshing process between the two or more gears. In order to obtain better results, it is possible to model the elastic element as a nonlinear spring.

Although gear dynamics has been studied for decades, few studies present a formulation intended for the dynamic response of full geartrain systems that contain multiple gear meshes, flexible shafts, bearings, and housing structures. There are few reliable computational tools for the dynamic analysis of general gear configurations. Some models exist, but they are limited by simplified modeling of gear tooth mesh interfaces, two-dimensional models that neglect outof-plane behavior, and models specific to a single gear configuration. General three-dimensional 
finite element models for dynamic response are rare because they require a significant computational effort. This is accomplished by many time steps required for the transient response to diminish, so that steady state data can be obtained. This study attempts to fill this gap with a general finite element formulation that can be used for full gearbox dynamic analyses.

Dynamic transmission error is taken as the parameter for the modelling of noise in geared transmission. In the last two decades there is plenty of work has been concentrating on modelling of the dynamic transmission error for spur and helical gears and representing the influence of the dynamic transmission errors on the level of noise in the geared transmission. Lately, there have been several experiments conducted in order to isolate particular noise effects like noise coming from bearing, housing noise, meshing action noise and backlash noise simply by measuring the dynamic transmission error. Some of the earliest models are represented in [4] and [5].

For different analysis purposes, there are several modelling choices such as a simple dynamic factor model, compliance tooth model, torsional model, and geared rotor dynamic model, [6]. Using the free vibration analysis critical para-meters such as natural frequencies and vibration modes that are essential for almost all dynamic investigations can be calculated. The free vibration properties are very useful for further analyses of planetary gear dynamics, including eigen-sensitivity to design parameters, natural frequency veering, planet mesh phasing, and parametric instabilities from mesh stiffness variations, [7] and [8]. It is also necessary to systematically study natural frequency and vibration mode sensitivities and their veering characters to identify the parameters critical to gear vibration. In addition, practical gears may be mistuned by mesh stiffness variation, manufacturing imperfections and assembling errors. For some symmetric structures, such as turbine blades, space antennae, and multispan beams, small disorders may dramatically change the vibration, [9]. The following articles [10] and [11], related to the nonlinear analysis of dynamic behavior of gears, using experimental methods and the application of FEM.
Based on the results of the experiments conducted during the gear vibration research, it is possible to conclude that the excitation is restored every time when a new pair of teeth enters the mesh. Vibrations with natural frequencies dominate the vibration spectrums. The internal dynamic forces in teeth mesh, vibration and noise are consequences of the: change in teeth deformation, teeth impact, gear inertia due to measure and teeth shape deviation [12].

Paper [13] presents two models of the geared transmission with two or more shafts. The first approach gives a model based on the rigid rotors coupled with rigid gear teeth, with mass distributions not balanced and in the form of the mass particles as the series of the mass debalances of the gears in multistep gear transmission. By a very simple model it is possible to conduct a useful investigation of the nonlinear dynamics of the multistep gear transmission and nonlinear phenomena in free and forced dynamics. This model is suitable to explain source of vibrations and big noise, as well as no stability in gear transmission dynamics. Layering of the homoclinic orbits in phase plane is a source of a sensitive dependence on the nonlinear type of regime of gear transmission system dynamics. The second approach gives a model based on the two-step gear transmission taking into account the deformation and creeping as well as viscoelastic teeth gears coupling. Our investigation was focused on a new model of the fractional order dynamics of the gear transmissiont. For this model we obtained analytical expressions for the corresponding fractional order modes like one frequency eigen vibrational modes. Generalization of this model to the similar model of the multistep gear transmission is quite simple.

The model in this paper represents a typical transmission model with three shafts. Starting with the first gear pair, a meshing action is observed for all gear meshes simultaneously using no additional assumptions concerning the gear geometry or the meshing action boundary and load conditions. The boundary conditions on the gear-shaft connections are assumed to be equal to zero. The internal dynamic forces are obtained as a result of the first step of the nonlinear quasi-static analysis and are taken as an input for further analysis. The procedure described can be modified for the 
purpose of calculation of different types of geared systems simply by combining different steps in the described analysis and different configurations of the gears and shafts. It is optional which of the mentioned steps will be of the highest priority, and depends, of course, of the purpose of the concrete analysis.

\section{FINITE ELEMENT MODEL OF THE SPUR GEAR TRANSMISSION}

Starting with one gear pair, a meshing action is observed using no additional assumptions concerning the gear geometry or the meshing action boundary and load conditions. A numeric experiment is developed simply by using the boundary conditions on the gear-shaft connection, which are assumed to equal zero. The software that is developed for the purpose of dynamic analysis of the gear-boxes can be used to obtain the following results from such model:

a) forces that arise in gear contact during the gear meshing action as a result of the incremental quasi-static series of analysis [8] to [10], for each meshing action time step,

b) the comprehensive modal analysis for the gear pair, and

c) the forces obtained in a) will be used further as an input for the nonlinear dynamic analysis. For the purpose of this paper, it is assumed that the obtained force is a harmonic function and in form:

$$
F_{n}=F_{o} \sin \omega t,
$$

where $F_{o}$ is the resultant force for the observed meshing action time step,

d) Finally, the dynamic analysis of the gear meshing action is conducted [10]. The contact load as inner dynamic load is taken as an input value obtained in a) and approximated using harmonic function, as it is described in c).

The developed software can be modified for the purpose of calculation of different types of geared systems. It is optional which of the mentioned steps will be of the highest priority, and it depends on the purpose of the concrete analysis. That is not of interest here, and therefore will not be discussed.

The gears analyzed in this paper are the ones from the deep drilling machine gear set, [14]. The gear geometries are generated using the software developed by the authors, [13] to [19], and adapted for the SALOME platform [40]. The obtained geometries are transferred to SALOME mesh generation software and discretized using four node tetrahedral elements there (Fig. 1).

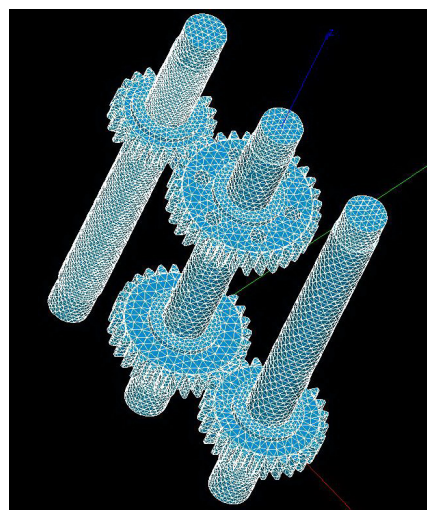

Fig. 1. Gear transmission model

Mesh parameters of the geared system are:

- number of nodes: 19209 ,

- number of elements: 102868 ,

Table 1. Constructive transmission parameters

\begin{tabular}{|l|c|c|c|c|}
\hline \multicolumn{1}{|c|}{ Parameter } & Gear 1 & Gear 2 & Gear 3 & Gear 4 \\
\hline Number of teeth & 27 & 30 & 33 & 22 \\
\hline Modul [m] & 0.003 & 0.003 & 0.003 & 0.003 \\
\hline Pitch circle diameter [m] & 0.081 & 0.090 & 0.099 & 0.066 \\
\hline Addendum circle diameter [m] & 0.087 & 0.096 & 0.106 & 0.072 \\
\hline Base circle diameter [m] & 0.073 & 0.0828 & 0.0918 & 0.0588 \\
\hline Measurement teeth number [m] & 0.004 & 0.004 & 0.004 & 0.003 \\
\hline Standard angle [degrees] & 20 & 20 & 20 & 20 \\
\hline Axial distance [m] & 0.081 & 0.081 & 0.081 & 0.099 \\
\hline
\end{tabular}


- number of elements of shaft 1 (staring from left hand side): 23618 ,

- number of elements of shaft 2 (middle): 30034 ,

- number of elements of shaft 3 (right bottom): 1586. Table 1.

Gear geometry parameters are given in

Displacement boundary conditions (Fig. 2) are set on the shaft-bearing connections nodes. The displacement boundary conditions on the axial bearing connection nodes are set to be zero in all degrees of freedom, and for the radial bearing connection nodes this displacement is set to be zero only in $\mathrm{X}, \mathrm{Y}$ directions.

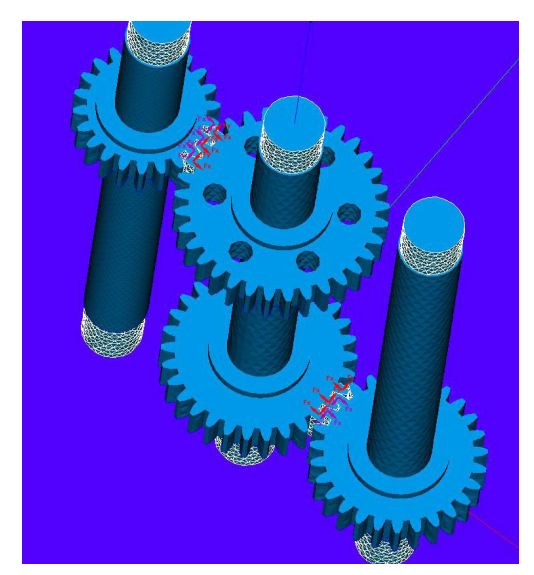

Fig. 2. Displacement and force boundary conditions (right)

Load boundary conditions are generated on the meshing teeth on edges that are opposite to the contact surfaces of each tooth, like [26]. The form of the load function is taken according to Eq. (1) with amplitude obtained from the nonlinear static analysis. This analysis helps determine the form of the amplitude force distribution in gear mesh. Detailed procedure on how the force is taken from nonlinear static analysis will not be discussed in detail here. The force distribution on other transmission elements is calculated in the same way.

All other meshing conditions are not taken into consideration. The following assumptions are made:

It is assumed that the contact is without friction:
- There is no sliding between the teeth during the meshing action.

- The transmission functions in constant temperature field. All other thermodynamic effects can be neglected.

- The proportional damping is used according to

$$
\mathbf{C}=2 \beta \mathbf{M}+\alpha \mathbf{K} .
$$

The continuum discretization is done using tetrahedral finite elements with linear approximation of the finite element geometry.

\section{ANALYTIC MODEL OF THE SPUR GEAR TRANSMISSION}

The transmission model in Fig. 1 can be simplified using the transmission model in Fig. 3 for dynamic analysis [1] to [3], [10], [27] and [31].

This class of dynamic models can be used for the analysis of the oscillation parameters of the transmission, only if meshing functions of the stiffness and dumping are known. As this is not the case, it is necessary to experimentally obtain the form of the mesh stiffness (dumping) of the geared mesh, or to use other means like finite elements method to obtain unknown stiffness/ dumping functions.

The solution for the differential equations given in Eq. (2) is not possible without explicitly defined mesh stiffness and dumping functions, because of the fact that the equations are nonlinear functions of time and the solution can be obtained only using numeric methods.

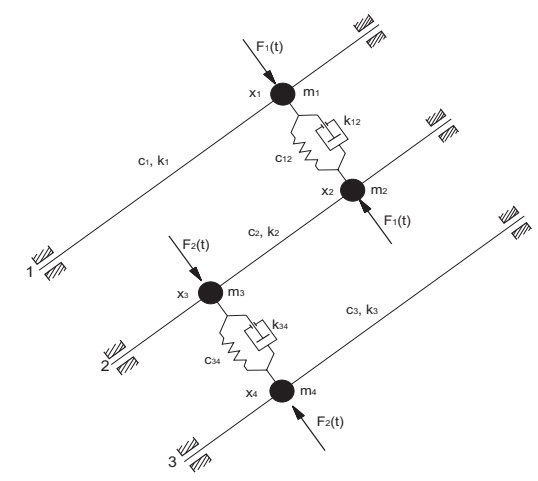

Fig. 3. A simplified dynamic model of the geared transmission on Fig. 1 
The differential equation [2], [3], [20] to [22] and [24] of the model in Fig. 3 are:

$$
\begin{gathered}
m_{1} \ddot{x}_{1}+\left(c_{1}+c_{12}\right) x_{1}-c_{12} x_{2}+ \\
+\left(k_{1}+k_{12}\right) \dot{x}_{1}-k_{12} \dot{x}_{2}=F_{1}(t), \\
m_{2} \ddot{x}_{2}+\left(c_{2}+c_{12}\right) x_{2}-c_{12} x_{1}-c_{2} x_{3}+ \\
+\left(k_{2}+k_{12}\right) \dot{x}_{2}-k_{12} \dot{x}_{1}-k_{2} \dot{x}_{3}=-F_{1}(t), \\
m_{3} \ddot{x}_{3}+\left(c_{2}+c_{34}\right) x_{3}-c_{34} x_{4}-c_{2} x_{2} \\
+\left(k_{2}+k_{34}\right) \dot{x}_{3}-k_{34} \dot{x}_{4}-k_{2} \dot{x}_{2}=F_{2}(t), \\
m_{4} \ddot{x}_{4}+\left(c_{3}+c_{34}\right) x_{4}-c_{34} x_{3}+ \\
+\left(k_{3}+k_{34}\right) \dot{x}_{4}-k_{34} \dot{x}_{3}=-F_{2}(t),
\end{gathered}
$$

where $m_{i}(i=1, \ldots, 4)$ are equivalent masses of transmission elements, $c_{i}$ are shaft stiffness $(i=1, \ldots, 3), k_{i}$ are shaft dumping $(i=1, \ldots, 3), c_{12}$, $c_{34}$ are gear mesh stiffness functions depending on $t, k_{12}, k_{34}$ are gear mesh dumping functions depending on $t$.

Shaft stiffness/dumping outside of the gears on the shaft 2 are not considered.

\section{STRESS AND STRAIN STATE ANALYSIS USING STRESS AND STRAIN TENSOR INVARIANTS}

The calculation of the component stresses and strains is done by means of the nonlinear FEM using already described procedure.

Starting from known component stresses as components of tensor $\mathbf{N}$, it is possible to obtain stress tensor invariants in every node after the finite elements analysis is done, [3], [23] to [31]. Since:

$$
\begin{gathered}
f\left(\sigma_{o}\right)=\left|\mathbf{N}-\sigma_{o} \mathbf{I}\right|= \\
=\left|\begin{array}{ccc}
\sigma_{x}-\sigma_{o} & \tau_{x y} & \tau_{x z} \\
\tau_{x y} & \sigma_{y}-\sigma_{o} & \tau_{y z} \\
\tau_{x z} & \tau_{y z} & \sigma_{z}-\sigma_{o}
\end{array}\right|=0,
\end{gathered}
$$

yields:

$$
-\left(\sigma_{o}^{3}-L_{1} \sigma_{o}^{2}+L_{2} \sigma_{o}-L_{3}\right)=0 .
$$

Using Eq. (3) or its algebraic form Eq. (4) it is possible to obtain the principal stresses as functions of stress invariants $L_{1}, L_{2}$ and $L_{3}$, using Eqs. (5) to (7) as a system of three linear algebraic equations with unknown principal stresses, [25] to [31]. That yields the functional dependency between principal stress and stress invariants in form: $\sigma_{o}=f\left(L_{1}, L_{2}, L_{3}\right)$. Therefore:

$$
\begin{aligned}
L_{1} & =f\left(\sigma_{1}, \sigma_{2}, \sigma_{3}\right)=\sigma_{1}+\sigma_{2}+\sigma_{3}=\operatorname{tr}(\mathbf{G}), \\
L_{2} & =f\left(\sigma_{1}, \sigma_{2}, \sigma_{3}\right)=\sigma_{1} \sigma_{2}+\sigma_{2} \sigma_{3}+\sigma_{1} \sigma_{3}= \\
& =\frac{1}{2}\left(\operatorname{tr}\left(\mathbf{G}^{2}\right)-\operatorname{tr}(\mathbf{G})^{2}\right),
\end{aligned}
$$

and

$$
L_{3}=f\left(\sigma_{1}, \sigma_{2}, \sigma_{3}\right)=\sigma_{1} \sigma_{2} \sigma_{3}=\operatorname{det}(\mathbf{G}),
$$

where Eq. (8) is a principal stress tensor in form:

$$
\mathbf{G}=\left[\begin{array}{ccc}
\tilde{A}_{1} & & \\
& \tilde{\mathrm{A}}_{2} & \\
& & \tilde{\mathrm{A}}_{3}
\end{array}\right] \text {. }
$$

When the component stresses are known, it is also possible to obtain the equations of the main stress directions. The principal stress directions are directions that define coordinate system of principal directions, where there are no shear stresses in defined planes.

When the principal stresses are different, $\sigma_{1} \neq \sigma_{2} \neq \sigma_{3}$, the maximal values of the shear stresses are found in the three normal planes, where the principal axis 1 and one of these planes are collinear, and the angles between the other principal planes and the mentioned plane are 45 degrees. The maximum values of the shear stresses are obtained in the following from:

$$
\begin{gathered}
\tau_{\text {(I) }}= \pm \frac{\sigma_{2}-\sigma_{3}}{2}, \quad \tau_{\text {(II) }}= \pm \frac{\sigma_{2}-\sigma_{1}}{2}, \\
\tau_{\text {(III) }}= \pm \frac{\sigma_{1}-\sigma_{2}}{2} .
\end{gathered}
$$

There are no shear stresses in principal planes. On the other hand, in maximal shear stress planes, there are stresses with values given in the form:

$$
\begin{gathered}
\sigma_{\text {(I) }}=\frac{\sigma_{2}+\sigma_{3}}{2}, \quad \sigma_{\text {(II) }}=\frac{\sigma_{1}+\sigma_{3}}{2}, \\
\tau_{\text {(III) }}=\frac{\sigma_{1}+\sigma_{2}}{2} .
\end{gathered}
$$

As already stated, the principal directions can be obtained from component stresses using the following relations: 


$$
\frac{\alpha_{0}}{K_{31}}=\frac{\beta_{0}}{K_{32}}=\frac{\gamma_{0}}{K_{33}}=C_{0},
$$

or

$$
\begin{gathered}
\frac{\alpha_{0}}{\left|\begin{array}{cc}
\tau_{x y} & \tau_{x z} \\
\sigma_{y}-\sigma_{0} & \tau_{y z}
\end{array}\right|}=\frac{\beta_{\mathrm{o}}}{-\left|\begin{array}{cc}
\sigma_{x}-\sigma_{\mathrm{o}} & \tau_{x z} \\
\tau_{x y} & \tau_{y z}
\end{array}\right|}= \\
=\frac{\gamma_{\mathrm{o}}}{\left|\begin{array}{cc}
\sigma_{x}-\sigma_{\mathrm{o}} & \tau_{x y} \\
\tau_{x y} & \sigma_{y}-\sigma_{\mathrm{o}}
\end{array}\right|}=C_{\mathrm{o}},
\end{gathered}
$$

the system is defined if condition Eq. (13) is satisfied:

$$
\alpha_{o}^{2}+\beta_{o}^{2}+\gamma_{o}^{2}=1
$$

The relations in Eqs. (11) and (12) should be taken for $s=1,2,3$. They give the equations for the three main stress directions represented with three direction cosines, with total of nine direction cosines.

Depending on the value of the principal invariants, the properties of the main stresses are defined:

a) if $L_{3}>0$, the roots (principal stresses) given in Eq. (8) are positive and different;

b) if $L_{3}<0$, there are negative roots (principal stresses); and

c) if $L_{3}=0$, one of the roots (principal stresses) is equal zero.

The same discussion can be applied for the strains. Starting from Eq. (14):

$$
\left|\begin{array}{ccc}
\varepsilon_{x}-\varepsilon_{o} & \gamma_{x y} & \gamma_{x z} \\
\gamma_{x y} & \varepsilon_{y}-\varepsilon_{o} & \gamma_{y z} \\
\gamma_{x z} & \gamma_{y z} & \varepsilon_{z}-\varepsilon_{o}
\end{array}\right|=0,
$$

yields:

$$
-\left(\varepsilon_{o}^{3}-J_{1} \varepsilon_{o}^{2}+J_{2} \varepsilon_{o}-J_{3}\right)=0,
$$

where $J_{1}, J_{2}$, and $J_{3}$ are known invariants of the strain tensor obtained from known strain components of the geared transmission. The solutions of the Eq. (15) are principal strains given. For the principal directions, the principal strains build the strain tensor in form Eq. (16):

$$
\begin{aligned}
& \mathbf{S}=\left(\begin{array}{lll}
\varepsilon_{1} & & \\
& \varepsilon_{2} & \\
& & \varepsilon_{3}
\end{array}\right), \\
& J_{1}=f\left(\varepsilon_{1}, \varepsilon_{2}, \varepsilon_{3}\right)=\varepsilon_{1}+\varepsilon_{2}+\varepsilon_{3}=\operatorname{tr}(S), \\
& J_{2}=f\left(\varepsilon_{1}, \varepsilon_{2}, \varepsilon_{3}\right)=\varepsilon_{1} \varepsilon_{2}+\varepsilon_{2} \varepsilon_{3}+\varepsilon_{1} \varepsilon_{3}= \\
& =\frac{1}{2}\left(\operatorname{tr}\left(S^{2}\right)-\operatorname{tr}(S)^{2}\right) \text {, } \\
& J_{3}=f\left(\varepsilon_{1}, \varepsilon_{2}, \varepsilon_{3}\right)=\varepsilon_{1} \varepsilon_{2} \varepsilon_{3}=\operatorname{det}(S) \text {. }
\end{aligned}
$$

Analogue to Eqs. (11) to (13) for the principal stresses, it is possible to obtain the equation of the principal strains by solving the system of Eqs. (17) to (19).

The principal strain directions can be obtained in the following form:

$$
\begin{gathered}
\frac{\alpha_{o}}{\left|\begin{array}{cc}
\gamma_{x y} & \gamma_{x z} \\
\varepsilon_{y}-\varepsilon_{o} & \gamma_{y z}
\end{array}\right|-\left|\begin{array}{cc}
\varepsilon_{x}-\varepsilon_{o} & \gamma_{x z} \\
\gamma_{x y} & \gamma_{y z}
\end{array}\right|}= \\
=\frac{\gamma_{o}}{\left|\begin{array}{cc}
\varepsilon_{x}-\varepsilon_{o} & \gamma_{x y} \\
\gamma_{x y} & \varepsilon_{y}-\varepsilon_{o}
\end{array}\right|}=C_{o}, \\
\alpha_{o}^{2}+\beta_{o}^{2}+\gamma_{o}^{2}=1 .
\end{gathered}
$$

Depending on the value of the principal invariants $J_{1}, J_{2}$ and $J_{3}$, the properties of the principal strains are for example:

a) if $J_{3}>0$, the roots (principal strains) of Eq. (7) are positive and different.

b) if $J_{3}<0$, there are negative roots (principal strains), and

c) if $J_{3}=0$, on of the roots (principal strains) is equal zero.

\section{RESULTS}

Using the above procedures, the results are obtained for the geared transmission in Fig. 1, using boundary conditions presented in Fig. 2 using transmission parameters given in Table 1 .

Transmission load distribution along the line of contact for each transmission gear pairs given in Fig. 4, and distribution of loads on the transmission elements for $t=0.02$ is given in Fig. 5 as an output from the nonlinear dynamic analysis of the geared transmission. 
Additional results for strain distribution along the line of contact for each gear par is given in Fig. 8, and Von Mises stress distribution along the line of contact for each transmission gear par and each time step (Fig. 7) together with distribution of Von Mises stress on the transmission elements for $\mathrm{t}=0.02$ is presented in Fig. 6.

Work methodology previously tested on simple examples from literature [7] to [11], [28] and [30] and obtained a good coincidence of results.

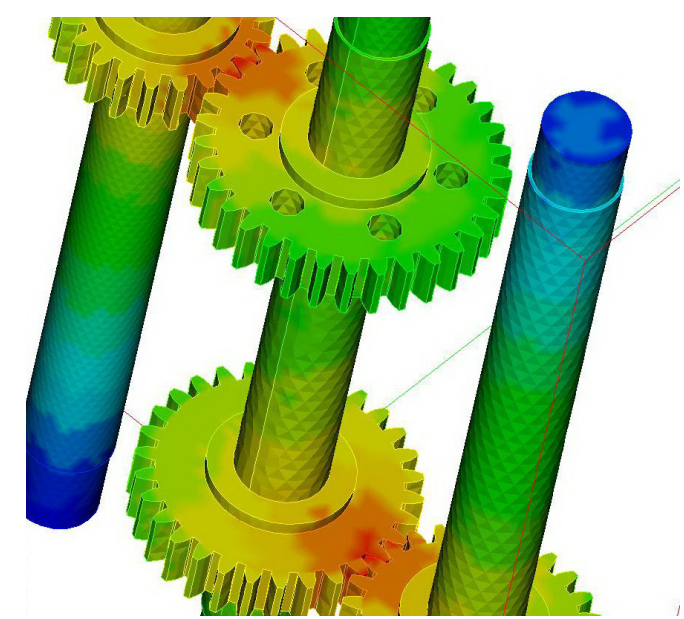

Fig. 4. Transmission load distribution in time step $t=0.02$

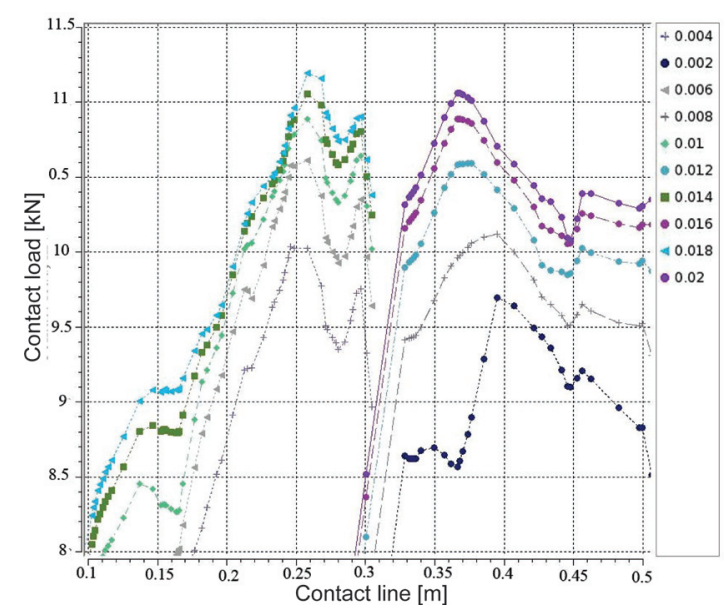

Fig. 5. Load distribution along the line of contact for each transmission gear par $(t=0$ to $t=0.02)$
The given results are input results for the calculations of principal invariants in each node for each and every element of the presented geared transmission. An example of the principal stress and strain direction calculation for the selected nodes in contact is presented in Fig. 9 and corresponding Tables 2 and 3.

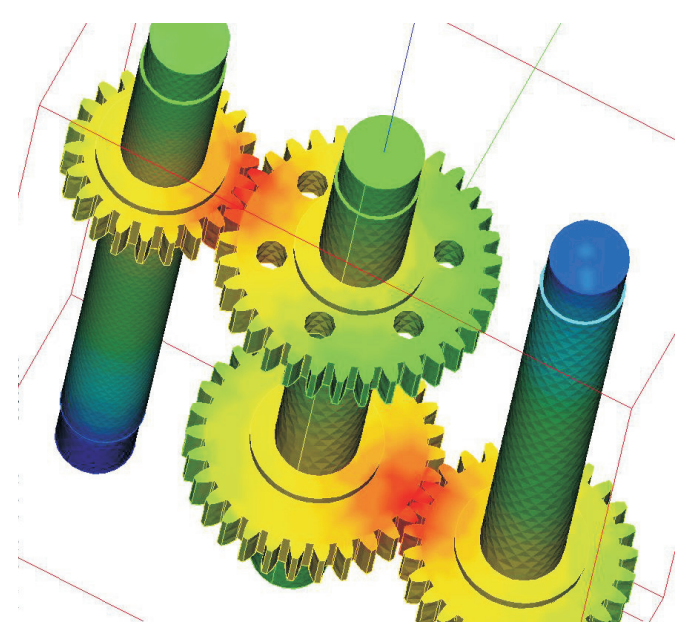

Fig. 6. Von Mises stress distribution on the transmission elements for $t=0.02$

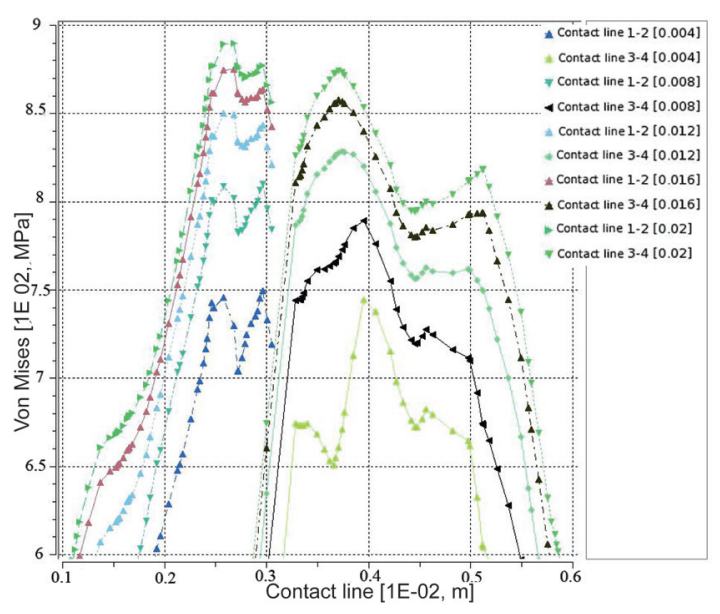

Fig. 7. Von Mises stress distribution along the line of contact for each transmission gear par $(t=0$

$$
\text { to } t=0.02 \text { ) }
$$

The distribution of the principal invariants in the zone of contact for each transmission gear pair is presented in Figs. 10 to 13, as a result of the software developed by the authors that can be used for the detailed transmission analysis. 


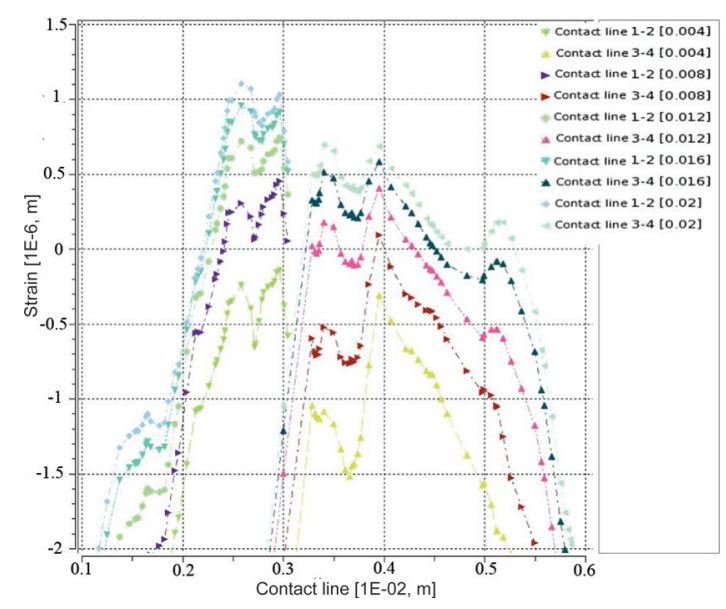

Fig. 8. Strain distribution along the line of contact for each transmission gear par

$$
(t=0 \text { to } 0.02)
$$

a)

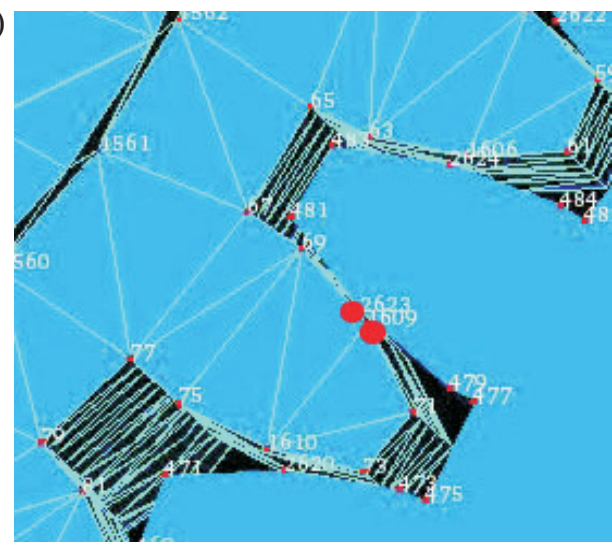

b)

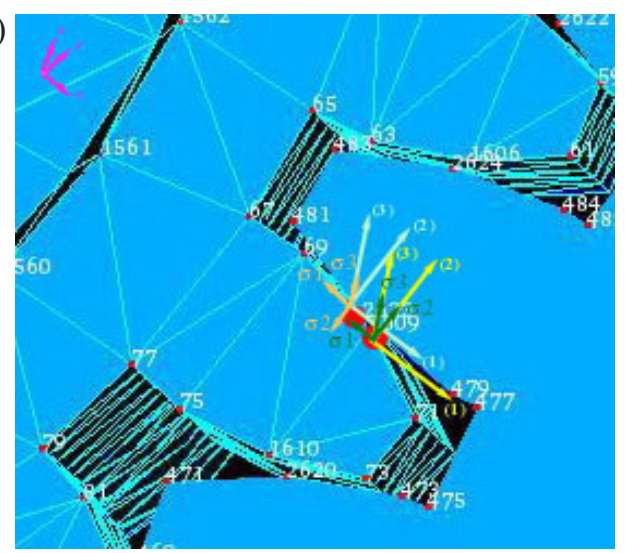

Fig. 9. a) Nodes which are used for calculation example of the stress and strain state, b) example of the graphic representation of the principal stress analysis results in chosen nodes

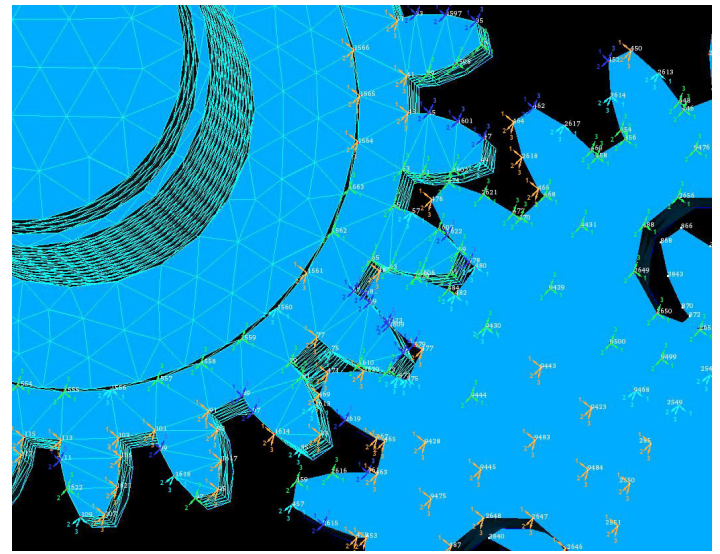

Fig. 10. Contact strain tensor invariants for the gear pair 1-2, for $t=0.02$

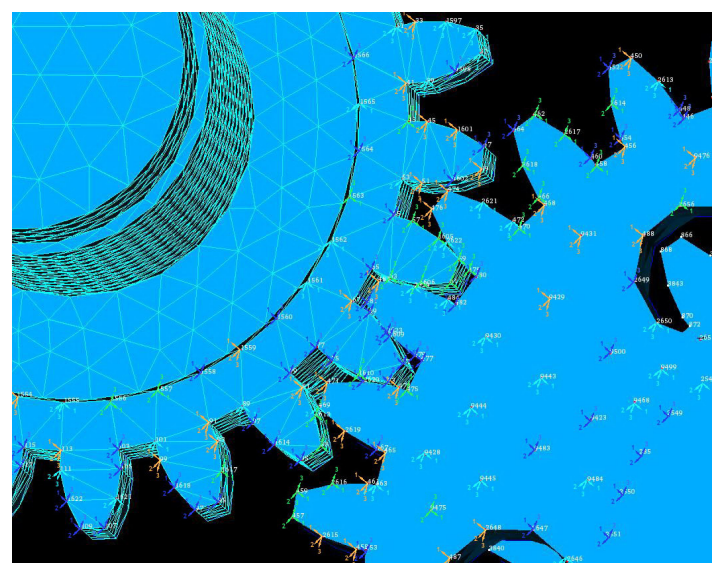

Fig. 11. Contact stress tensor invariants for the gear pair 1-2, for $t=0.02$

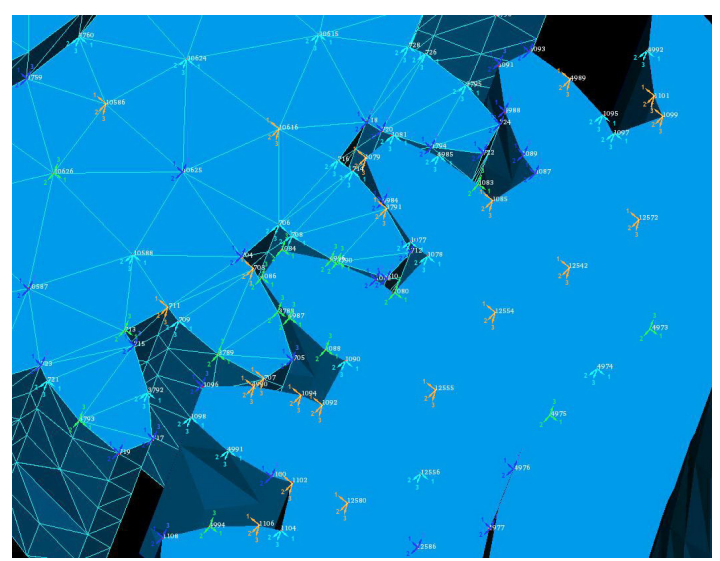

Fig. 12. Contact stress tensor invariants for the gear pair $3-4$, for $t=0.02$ 


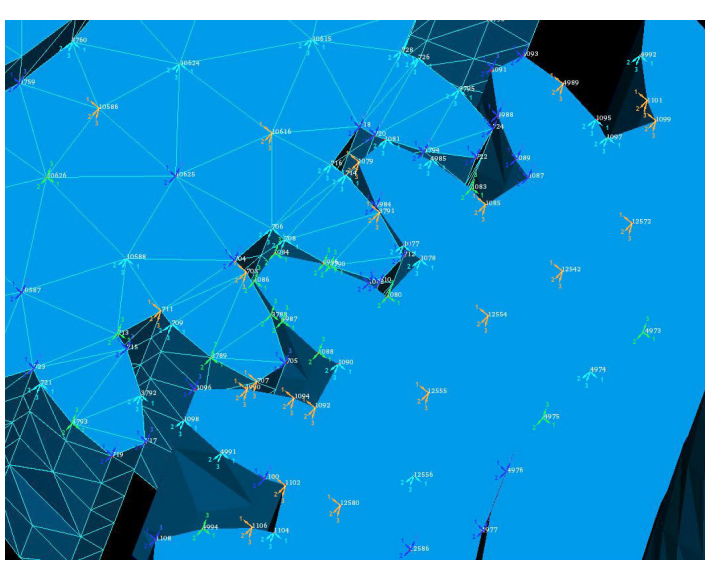

Fig. 13. Contact strain tensor invariants for the gear pair 3-4, for $t=0.02$

Work methodology previously tested on simple examples from literature [7] to [11], [28] and [30] and obtained a good coincidence of results.

\section{CONCLUSIONS}

In this paper has been shown how the general finite elemente method can be applied to study dynamic behavior in the case of the real model of the geared set.

A novel approach for the geared transmission dynamic analysis is developed. Using several incremental finite elements procedures, it is possible to obtain a series of states of the geared transmission in every integration time step of the differential equations of motion. Since the conditions in which the dynamic analysis is done are quasistatic, suggested method approximates very well the real working conditions of the transmission. On the other hand, as every dynamic calculation, it is exhaustive and time consuming.

For the observed model of gear transmissions, the analysis distribution of stress and strain invariants has been done.

The selected point that are in contact, are determined by the value of the main stresses and main directions of the observed time-steps.

Based on the results, it can be concluded that there is a change in the directions of principal stresses in the contact zone. This causes arise and changes in the values the principal stresses, that is stress invariants.
Table 2. Component stresses and strains in node: 1609 , principal stress, strain invariants, principal stresses and principal strains and appropriate principal directions, for $t=0.02$

\begin{tabular}{|c|c|c|}
\hline \multicolumn{3}{|c|}{ Node: 1609} \\
\hline$\sigma_{x}[\mathrm{~Pa}]$ & $\sigma_{y}[\mathrm{~Pa}]$ & $\sigma_{z}[\mathrm{~Pa}]$ \\
\hline $2.437 \mathrm{E}+09$ & $8.759 \mathrm{E}+08$ & $6.726 \mathrm{E}+08$ \\
\hline$\tau_{x v}[\mathrm{~Pa}]$ & $\tau_{x z}[\mathrm{~Pa}]$ & $\tau_{y z}[\mathrm{~Pa}]$ \\
\hline $1.949 \mathrm{E}+08$ & $-9.431 E+06$ & $6.974 \mathrm{E}+07$ \\
\hline$\alpha$ & $\beta$ & $\gamma$ \\
\hline 1.56 & 1.62 & $5.10 \mathrm{E}-02$ \\
\hline 1.46 & 2.64 & 1.09 \\
\hline 1.57 & 1.56 & $7.13 \mathrm{E}-03$ \\
\hline$L_{1}$ & $L_{2}$ & $L_{3}$ \\
\hline $3.99 \mathrm{E}+09$ & $-1.38 \mathrm{E}+19$ & $-6.89 \mathrm{E}+27$ \\
\hline$\sigma_{1}[\mathrm{~Pa}]$ & $\sigma_{2}[\mathrm{~Pa}]$ & $\sigma_{3}[\mathrm{~Pa}]$ \\
\hline$-2.54 \mathrm{E}+09$ & $4.47 \mathrm{E}+08$ & $6.08 \mathrm{E}+09$ \\
\hline$\varepsilon_{x}[\mu \mathrm{m}]$ & $\varepsilon_{x}[\mu \mathrm{m}]$ & $\varepsilon_{x}[\mu \mathrm{m}]$ \\
\hline 939.480 & -27.195 & -153.040 \\
\hline$\gamma_{x v}[\mu \mathrm{m}]$ & $\gamma_{x z}[\mu \mathrm{m}]$ & $\gamma_{v z}[\mu \mathrm{m}]$ \\
\hline 241.311 & -11.676 & 86.346 \\
\hline$\alpha$ & $\beta$ & $\gamma$ \\
\hline 1.55 & 2.78 & 1.21 \\
\hline 1.37 & 2.58 & 2.09 \\
\hline 1.32 & 2.56 & 2.09 \\
\hline$J_{1}$ & $J_{2}$ & $J_{3}$ \\
\hline $7.60 \mathrm{E}+01$ & $-7.14 \mathrm{E}+04$ & $2.00 \mathrm{E}+06$ \\
\hline$\varepsilon_{1}[\mu \mathrm{m}]$ & $\varepsilon_{2}[\mu \mathrm{m}]$ & $\varepsilon_{3}[\mu \mathrm{m}]$ \\
\hline$-2.14 \mathrm{E}+02$ & $-2.93 \mathrm{E}+01$ & $3.19 \mathrm{E}+02$ \\
\hline
\end{tabular}

In the literature are present similar procedures [7] to [10] and they were used as reference material for the composition and verification of models and results .

But, in this paper, a new method for the results analysis, together with developed software, is used for obtaining of the principal stress and strain state of the geared transmission, using principal stress and strain invariants as calculation parameters. The software allows generalized analysis of every system for which this kind of analysis can be used. 
Table 3. Component stresses and strains in node: 2623, principal stress, strain invariants, principal stresses and principal strains and appropriate principal directions, for $t=0.02$

\begin{tabular}{|c|c|c|}
\hline \multicolumn{3}{|c|}{ Node: 2623} \\
\hline$\sigma_{x}[\mathrm{~Pa}]$ & $\sigma_{y}[\mathrm{~Pa}]$ & $\sigma_{z}[\mathrm{~Pa}]$ \\
\hline $2.088 \mathrm{E}+09$ & $1.229 \mathrm{E}+09$ & $1.053 \mathrm{E}+09$ \\
\hline$\tau_{x y}[\mathrm{~Pa}]$ & $\tau_{x z}[\mathrm{~Pa}]$ & $\tau_{y z}[\mathrm{~Pa}]$ \\
\hline $5.508 \mathrm{E}+07$ & $-3.036 \mathrm{E}+07$ & $3.852 \mathrm{E}+07$ \\
\hline$\alpha$ & $\beta$ & $\gamma$ \\
\hline 1.57 & 1.57 & $6.26 \mathrm{E}-03$ \\
\hline 1.57 & 1.57 & $5.77 \mathrm{E}-03$ \\
\hline 1.59 & 1.60 & $3.61 \mathrm{E}-02$ \\
\hline$L_{1}$ & $L_{2}$ & $L_{3}$ \\
\hline$-4.36 \mathrm{E}+09$ & $-7.46 \mathrm{E}+18$ & $2.21 \mathrm{E}+28$ \\
\hline$\sigma_{1}[\mathrm{~Pa}]$ & $\sigma_{2}[\mathrm{~Pa}]$ & $\sigma_{3}[\mathrm{~Pa}]$ \\
\hline$-4.97 \mathrm{E}+09$ & $-1.83 \mathrm{E}+09$ & $2.44 \mathrm{E}+09$ \\
\hline$\varepsilon_{x}[\mu \mathrm{m}]$ & $\varepsilon_{x}[\mu \mathrm{m}]$ & $\varepsilon_{x}[\mu \mathrm{m}]$ \\
\hline-668.191 & -136.320 & -27.790 \\
\hline$\gamma_{x y}[\mu \mathrm{m}]$ & $\gamma_{x z}[\mu \mathrm{m}]$ & $\gamma_{y z}[\mu \mathrm{m}]$ \\
\hline 68.191 & -37.592 & -47.688 \\
\hline$\alpha$ & $\beta$ & $\gamma$ \\
\hline 1.52 & 1.88 & $3.10 \mathrm{E}-01$ \\
\hline 1.77 & 2.94 & 1.53 \\
\hline 1.88 & 2.54 & $1.07 \mathrm{E}+00$ \\
\hline$J_{1}$ & $J_{2}$ & $J_{3}$ \\
\hline$-8.30 \mathrm{E}+01$ & $-5.06 \mathrm{E}+04$ & $2.66 \mathrm{E}+06$ \\
\hline$\varepsilon_{1}[\mu \mathrm{m}]$ & $\varepsilon_{2}[\mu \mathrm{m}]$ & $\varepsilon_{3}[\mu \mathrm{m}]$ \\
\hline$-2.45 \mathrm{E}+02$ & $-5.10 \mathrm{E}+01$ & $2.13 \mathrm{E}+02$ \\
\hline
\end{tabular}

On the basis of the results, shown in this paper, it has been concluded that the methodology developed to study the dynamic behaviour of complex systems is very efficient. It gives a lot of possibilities and can be easily upgraded for analysis of other effects [33] to [35].

The dynamic behavior and analysis of the stress and strain conditions that suggest that the system of only two gears is very complex and that it is almost impossible to include all the effects by such and similar research. This paper considers two pair gears, which makes the problem more complex.

Further research should be directed at studying the effects of mutual dynamic impact of teeth in engagement, as well as at including connection between the shaft and gear into the dynamic model and the like.

In accordance with the present trend of application of new materials, like in [36] to [39], authors will, in future studies, simulate the dynamic behavior of a gear made of composite materials and study the life of the gears at the cyclic load.

Based on the numerical results, i.e., on the presented and other diagrams, a general conclusion can be drawn: stress and strain distributions in the case of dynamic behavior of toothed gears is in accord with the results from the aforementioned literature. Thus, these results can be taken as relevant for further research.

\section{ACKNOWLEDGMENTS}

Parts of this research were supported by the Ministry of Sciences, Technologies and Development of Republic Serbia trough Mathematical Institute SANU Belgrade, State University of Novi Pazar and Faculty of Mechanical Engineering University of Niš Grants No. ON174001. "Dynamics of hybrid systems with complex structures. Mechanics of Materials."

\section{REFERENCES}

[1] Niemann, G., Winter, H. (1989). Maschinen elemente II and III. Springer Verlag, Berlin. (in German)

[2] Nikolic, V. (2004). Machine elements, theory, calculation, examples. Faculty of Mechanical Engineering, Kragujevac.

[3] Nikolic, V. (1999). Mechanical analysis of gears. Faculty of Mechanical Engineering, Cimpes, Kragujevac.

[4] Kahraman, A., Blankenship, G. W. (1988). Experiments on nonlinear dynamic behavior of an oscilator with clearance and periodically time-varying parameters. Journal of Applied Mechanics, vol. 64, p. 217-226, DOI:10.1115/1.2787276. 
[5] Kahraman, A., Singh, R. (1990). Nonlinear dynamics of a spur gear pair. Journal of Sound and Vibration, vol. 142, no. 1, p. 4975, DOI:10.1115/1.2787276.

[6] Blankenship, G.W., Singh, R. (1995). A New gear mesh interface dynamic model to predict multi-dimensional force couplung and excitation. Mechanism and Machine Theory, vol. 30, no. 1, p. 43-57, DOI:10.1016/0094-114X(94)00018-G.

[7] Lin, J., Parker, G. R. (1999). Analytical characterization of the unique properties of planetary gear free vibration. Transactions of the ASME, vol. 121, p. 316-321.

[8] Lin, J., Parker, G.R. (2001). Natural frequency veering in planetary gears. Mechanics of Structures and Machines, vol. 29, no. 4, p. 411-429, DOI:10.1081/SME100107620.

[9] Lin, J., Parker, G.R. (2002). Planetar gear parametric instability caused by mesh stiffness variation. Journal of Sound and vibration, vol. 249 , no. 1, p. 38-48, DOI:10.1006/jsvi.2001.3848.

[10] Parker, G.R., Vijayakar, M.S., Imajo, T. (2000). Non-linear dynamic response of a spur gear pair: modelling and experimental comparisons. Journal of Sound and vibration, vol. 237, no. 3, p. 435-455, DOI:10.1006/jsvi.2000.3067.

[11] Parker, G.R., Agashe, V., Vijayakar, M.S. (2000). Dynamic response of a planetary gear system using a finite element/ contact mechanics model. Transactions of the ASME, vol. 122, p. 304-310, DOI:10.1115/1.1286189.

[12] Agemi, M.F., Ognjanović, M. (2004). Gear vibration in supercritical mesh-frequency range. FME Transactions, vol. 32 , no. 2, p. 87-94.

[13] Hedrih-Stevanovic K., Nikolic-Stanojevic, V. (2010). A model of gear transmission fractional order system dynamics. Mathematical Problems in Engineering, from: http://www.hindawi.com/journals/ mpe/aip972873.html, accesed on 2010-0506.

[14] Dimitrijevic, D., Nikolic, V. (1998b). Eigenfrequencies analysis for the deep drilling machine gear set. The Scientific
Journal Facta Universates, Series Mechanical Engineering, vol. 1, no. 5, p. 29636.

[15] Dimitrijević, D., Nikolić, V. (1998a), Automatic finite elements mesh generation with eigenfrequencies and mode shapes calculations for vecihle gears. $M V M$, vol. 24, no. 2, p. 10-14.

[16] Nikolić, V., Dimitrijević, D. (1997a). On application of numerical methods in the studies of toothed gears. International Symposium "Machines and Mechanisms", p. 130-136.

[17] Nikolic, V., Dimitrijevic, D. (1997). Application of finite element method for calculation of the main forms of vibration of gear machine tools. VI North's symposium on mechanical gears, p. 91-96.

[18] Nikolić, V., Dimitrijević, D. (1998). Solving contact problems of elasticity theory application finite element method. Scientific Research and Development of a set of machine elements and systems IRMES, $\mathrm{p}$. 163-168.

[19] Nikolic, V., Maksimovic, K., Maksimovic, S. (2000). Fatigue life prediction of gear teeth under general load spectrum. International Conference Power Transmissions, Varna.

[20] Raškovic, D. (1989). The theory of elasticity, Scientific book, Beograd.

[21] Dolićanin, D., Đorđević, R., Dolićanin, Ć. (2011). Differential equations, existence of solutions, uniqueness of solution and numerical solution, State University of Novi Pazar.

[22] Atanacković, M.T., Dolićanin, Ć.D., Pilipović, S. (2011). Forced Oscillations of a Single Degree of Freedom System with Fractional Dissipation. Scientific Publications of the State University of Novi Pazar, Series A: Applied Mathematics, Informatics \& Mechanics, vol. 3, no. 1, p. 1-11.

[23] Zienkiewics, O.C. (1977). The finite element method, $3^{\text {rd }}$ edition, McGraw-Hill, London.

[24] Hedrih-Stevanovic K., Knežević, R. (2000). Structural stability of the planetary reductor nonlinear dynamics phase portrait. Facta Universitatis, Series: Mechanical Engineering, vol. 1, no. 7, p. 911-923. 
[25] Dimitrijevic, D., Nikolic, V. (2007). Eigenfrequence analysis of the spur gear pair with moving excentric masses on the body of one of the gears. FME Transactions, vol. 35 , no. 3, p. 157-163.

[26] Vedmar, L., Andersson, A. (2003). A method to determine dynamic loads on spur gear teeth and on bearings. Journal of Sound and Vibration, vol. 267, p. 1065-1084, DOI:10.1016/S0022-460X(03)00358-4.

[27] Dimitrijevic, D., Nikolić, V. (2007). Dynamic analysis of the stress and strain state of the spur gear pair. Scientific Technical Review, vol. 3-4, p. 20-24.

[28] Parker, G.R. (1998). On the Eigenvalues and critical speed stability of gyroscopic continua. Transactions of the ASME, vol. 65, p. 134-140.

[29] Dimitrijević, D., Nikolić, V., Atanasovska, I. (2007). Dynamic analysis of the stress and strain state of the spur gear pair. Scientific Technical Rewiew, vol. LVII, no. 3-4, p. 2025.

[30] Vinayak, H., Singh, R. (1998). Multi-body dynamics and modal analysis of compliant gear bodies. Journal of Sound and Vibration, vol. 210, no. 2, p. 171-214, DOI:10.1006/ jsvi.1997.1298.

[31] Nikolić, V., Dolićanin, Ć., Dimitrijević, D. (2009). Numerical modelling of dynamic behaviour of complex systems. $2^{\text {nd }}$ International Congress of Serbian Society of Mechanics (IConSSM).

[32] Nikolic, V., Dolićanin, C., Dimitrijevic, D. (2010). Numerical modelling of gear set dynamic behaviour. Scientific Technical Review, no. 3-4, p. 48-54.

[33] Dolicanin, C., Nikolic, V., Dolicanin, D. (2010). Application of finite difference method to study of the phenomenon in the theory of thin plates. Scientific Publications of the State University of Novi Pazar, Series A: Applied Mathematics, Informatics \& Mechanics, vol. 2, no. 1, p. 29-45.

[34] Agemi, F., Ognjanovic, M. (2010). Gear vibrations in supercritical meshfrequency range caused by teeth impacts. Strojniški vestnik - Journal of Mechanical Engineering, vol. 56, no. 10, p. 653-662.

[35] Nikolic, V., Dolicanin, C., Radojkovic, M. (2011). Application of finite element method of thin steel plate with holes. Technical Gazette, vol. 18, no. 1, p. 57-62.

[36] Stamenkovic, D., Maksimovic, K., NikolicStanojevic, V., Stupar, S. Vasovic, I. (2010). Fatigue life estimation of notched structural components. Strojniški vestnik - Journal of Mechanical Engineering, vol. 56, no. 12, p. 846-852.

[37] Maksimovic, S., Posavljak, S., Maksimovic, K., Nikolic-Stanojevic, V., Djurkovic, V. (2010). Total fatigue life estimation of notched structural components using low-cycle fatigue properties. Strain, vol. 47 , p. $341-349$, DOI: $10.1111 / \mathrm{j} .1475-$ 1305.2010.00775.x.

[38] Vijayakar, S.M. (1991), A combined surface integral and finite element solution for a three-dimensional contact problem. International Journal for Numerical Methods in Engineering, vol. 31, p. 524546.

[39] Wilson, E.L., Itoh, T. (1983). An eigensolution strategy for large systems. Computers and Structures, vol. 16, no. $1-4$, p. 259-265, DOI:10.1016/00457949(83)90166-9.

[40] Code Aster Salome platforms from: http:// www.code-aster.com, http://www.salomeplatform.org, accesed on 2000-02-15. 